\title{
GONSUMER FOOD SECURITY AND LABELING INTERVENTION ON FOOD PRODUGTS THROUGH PUBLIC POLICIES IN ROMANIA
}

\author{
Dacinia Crina Petrescu ${ }^{\text {1*, Ruxandra Mălina Petrescu-Mag }}{ }^{2}$, Florina Bran ${ }^{3}$ \\ and Carmen Valentina Rădulescu ${ }^{4}$ \\ 1), 2) Babes-Bolyai University, Cluj-Napoca, Romania \\ 3), 4) The Bucharest University of Economic Studies, Bucharest, Romania
}

Please cite this article as:

Petrescu, D.C., Petrescu-Mag, R.M., Bran, F. and

Rădulescu, C.V., 2018. Consumer Food Security and

Labeling Intervention on Food Products through

Public Policies in Romania. Amfiteatru Economic,

20(47), pp. 99-115.

\section{Article History}

Received: 15 September 2017

Revised: 8 October 2017

Accepted: 13 November 2017

\begin{abstract}
The correct understanding of consumers' food labeling knowledge and perceptions is a prerequisite to develop and implement coherent and appropriate food safety policies. One objective of the paper was to discover how often consumers access and use specific food label information. Another objective was to explore stakeholders' preferences for several public policy options relevant for food safety. In this respect, a survey on a sample of 312 Romanian consumers and the evaluation of several public policy options by four stakeholder groups (food producers and sellers, doctors, fitness trainers, and consumers) were carried out. The results revealed that the most frequently read types of information on the label were "expiration date" and "price", closely followed by "quantity" and "brand". Among tested public policies, those related to the traffic light labels and to the social interest messages with health claims were rewarded with high scores by investigated stakeholders. Although nutrition has a decisive impact on health state, nutrition information was not frequently read by people, thus justifying the implementation of a public policy meant to enhance consumers' interest in and reading frequency of nutrition information on food label.
\end{abstract}

Keywords: label, food safety, consumer, label reading behavior, public policy, Romania.

JEL Classification: D18, M31, Q18, R28

*Corresponding author,Dacinia Crina Petrescu - crina.petrescu@ tbs.ubbcluj.ro

The first three authors have equal contributions to this paper and, therefore, they are considered as first author. 


\section{Introduction}

The agro-food sector has undergone, over time, numerous interventions, some of which fall into the category of agricultural, environmental, health or consumer protection public policies, in order to guarantee food safety, animal welfare or to adapt the sector to increasing competition. Regarding consumer protection policies, they are divers and may refer to data protection, food safety, or ways to inform consumers. Food safety is a global concern that addresses various aspects of everyday life and it includes handling, preparing and storing food in a way that effectively reduces the risk of people becoming sick because of the consumed food (Santacruz, 2016). A healthy diet helps prevent malnutrition in all its forms, as well as a series of non-communicable diseases (WHO, 2015). Both healthy diet and food safety are components of food quality (along with other attributes that are considered by the consumer such as taste or color) (Aung and Chang, 2014). The presence of both is necessary at the same time, because the existence of one cannot compensate for the absence of the other. Thus, a product may appear nutritionally healthy but it may be unsafe (e.g., when it is contaminated with pathogens or with harmful chemicals) (Aung and Chang, 2014). It has been noticed that in order to adopt a balanced nutrition it is important to have knowledge both about nutrition and about food safety (Prell et al., 2005; Turconi et al., 2008; Maican, 2015).This knowledge can be partly acquired by reading the food label. The label is a tool that can help consumers to make choices that are healthy (which respect a balanced diet) and safe at the same time. For the promotion of a healthy diet, the World Health Organization (WHO) targets both policy makers and consumers: to the first category, WHO recommends to pore over regulatory and voluntary instruments, such as marketing policies, including food labeling, economic incentives or disincentives (i.e., subsidies, taxation); to consumers, WHO gives encouragements to demand healthy foods including through food labeling that ensures accurate, standardized and comprehensible information on nutrient contents in food (WHO, 2015).

The main objectives of this research were to discover how often consumers access and use specific food label information and to explore stakeholders preferences toward several public policy options relevant for food safety. This research direction is rooted in the fact that supporting the reading of label information, especially of the nutritional ones, is among the most prominent and far-reaching policy measures related to diet which can stimulate healthy eating (Graham et al., 2012) and with a decisive influence on health state (WHO, 2004). The premise of this research is that a correct understanding of consumers' food labeling knowledge and perceptions is a prerequisite to develop and implement coherent and appropriate safety food policies. This understanding is not an easy task, because deciding which foods to buy, serve and eat is embedded in a complexity of social relations and cultural concepts which attach meaning and status to food (Wilcock et al. 2004). The novelty of this research is given by an integrated image on label reading behavior - including premises, reading, and consequences - and by the scrutiny of a detailed list of label information, placed in the context of food safety debate. Moreover, for the first time, the knowledge about Romanian consumer label reading behavior was incorporated into three public policy scenarios, thus offering practical answers to food safety matters, backed up by choices made by stakeholders.

The paper includes a review of the scientific literature, the research methodology, and then, the research results are presented and discussed. These refer, on the one hand, to the label/front-of-pack (FOP) reading behavior (where the prerequisites of reading, reading 
itself and its consequences are analyzed). On the other hand, the results point out three public policy options on labeling designed to promote food safety and which are based on label reading information. Finally, the contributions of the paper and the possible directions for further research are summarized in the conclusions section.

\section{Review of the scientific literature}

Food safety has become an important food quality attribute over the last decades because food safety is no longer perceived by consumers as implied by the mere fact the product is on the shelves and consumers want to receive messages that reassured them that the food is safe (e.g., through labels certifying that the food item was obtained under the requirements of a food quality management systems) (Röhr et al., 2005). Viewed as a heterogeneous term, food safety can be interpreted in various forms and consumers' definitions of it are formed by individual perceptions. One of the most well-known definitions of food safety considers it as the inverse of food risk and states that it can be expressed as the probability of not suffering harm from consuming a food item (Henson and Traill, 1993).

Studies show that consumers are generally uncertain about the safety and quality of their food, despite the fact that there is a wide range of control instruments and, therefore, the food supply has never been safer and better monitored (Verbeke et al., 2007). Consumers are increasingly more selective in food purchasing due to concerns over safety in a neverending food alerts and scandals context, being proved that cleanliness, safety, and nutrition are among the desirable food characteristics sorted out by consumers (MohdNawi and Mohd Nasir, 2014). Thus, the label/front-of-package (FOP; front-of-pack; package of product) is carrier of food safety attributes, such as expiration date, number of calories, additives or the list of ingredients itself.

This paper highlighted consumer label/FOP reading behavior, namely premises, reading frequency, and consequences of noticing the lack of label/FOP information. In this paper, the "food label" and "front-of-pack" information refer to all types of information displayed on them and they were used as synonyms because front-of-pack information is often presented under the form of a label. The expression "front of pack" is used in the sense of product packaging (any part of it) that contains product information that is visible to consumer. The information displayed on the FOP includes nutrition information under the form of labeling (e.g., nutrition facts table), health claims (e.g., sugar-free, saturated fatfree) and other information such as producer, brand, etc. The words "label/FOP" were used in this paper in order to cover all these categories of information.

The results of the consumer behavior analysis were used to develop three public policy options on food safety that may have the capacity to guide toward healthier food purchase:

- the mandatory introduction of traffic light labels (TLLs);

- the mandatory use of social interest messages (SIM) with health claims;

- the continuation of the current situation, which signifies to "Do nothing".

Regarding the TLLs, studies revealed consumers' requests to have at hand several relevant nutrition information better highlighted on the FOP label, such as calories, sodium or transfat (Kim and Kim, 2009) and on consumers' support of the implementation of a single, 
standardized FOP system, with the nutrient-specific systems, such as TLLs (Emrich et al, 2014). TLLs ease consumers' comprehension of nutrition characteristics, in a context where lack of label understanding was found to be a main obstacle in front of label reading and healthy purchasing (Grunert et al, 2010). A large study on Canadian consumers showed that TLLs could reduce population intakes of calories, total fat, saturated fat, and sodium and, therefore, governments and policy makers should consider implementing a policy for the adoption of TLLs with the purpose to improve dietary intakes and reduce chronic disease risk (Emrich et al, 2017). Besides their advantages, TLLs were also criticized, mainly because they display only negative nutrients, making difficult the comparison of foods from the same category, which contain also positive nutrients and because they might disadvantage certain foods with important beneficial nutrients, where it is difficult to avoid red color for saturated fat (e.g., dairy products) (Tarabella and Voinea, 2013; Wartella et al., 2011).At international level, TLLs are voluntary labeling schemes. For example, in the UK, such a system was introduced in 2013, and it wasrevised in 2016 (Department of Health et al., 2016); France adopted in 2017 a similar five-color system (from green-tored), which guides consumers quickly and easily in understanding the nutritional value of aliments and it marks an important achievement in nutrition in the European Region of the WHO (WHO, 2017a). According to authors' best knowledge, there is, to date, no analysis of the national effects of implementing aTLLs system.

Social interest messages related to food can be useful as it has been noticed that familiarity with them improves citizens' perception of how healthy food is and it increases their acceptance (Lähteenmäki, 2013). Also, in a study on Italian consumers, health-related messages had a strong impact on vulnerable consumers - the elderly ones with health problems and low incomes (Cavaliere, Ricci and Banterle, 2015).

Unhealthy diet is a preventable risk factor that can be prevented and reduced through education and information. These actionscan determine consumers to make better nutrition choices, for instance by decreasing their total calories, saturated and trans-fat, salt, and sugar intake, responsible for many health problems. Studies casted light on the fact that education can have a positive impact on label reading behavior by increasing the time dedicated to label gazing (Pennings, Striano and Oliverio, 2014) and on improving diet, for example, by reducing fat consumption, which may positively impact on diet quality and decrease the risk of chronic disease related to fat consumption (Emrich and Mazier, 2009). Thus, the information provided on the label/FOP can educate consumers to develop healthier nutrition habits. World Health Organization considers nutrition labeling an essential part of its global strategy on diet, physical activity and health (WHO, 2004). Correct nutrition is important not only at micro (individual) level, but also at macro (national or larger) level because wrong nutrition increases health care costs, reduces productivity and slows economic growth (WHO, 2017b). Statistical data show the gravity of nutrition problems at global level: in 2014, approximately 1.9 billion adults worldwide were either overweight or obese and 462 million were underweight and in 2016, around 41 million children under the age of 5 years were overweight or obese, while 155 million were suffering from stunting (WHO, 2017b).

Efforts to improve knowledge and behaviors on labeling reading are essential to safeguard the health of consumers and also to endow them with valuable information and knowledge that may transform them in guardians of their families' health. In line with this view, the European Food and Nutrition Action Plan 2015-2020 (WHO, 2014) (targeting both EU and non-EU 
countries) focuses on food and nutrition as the leading factors in health and wellbeing in the European Region, in a context where food is considered as critical contributor to physical well-being and a major source of worry and stress (Rozin et al., 1999).

\section{Research methodology}

The research is based on a survey that used asample of 312 persons from Romania, interviewed by phone, during January-July 2017. Random phone numbers were generated and an interview was requested and carried on in the case of a positive answer. The positive response rate was $8 \%$. The limit of 312 interviews was determined by time and budget constraints. The final sample structure was as follows: $42 \%$ men and $58 \%$ women, $78 \%$ from urban areas and $22 \%$ from rural ones, $34 \%$ aged $18-25,49 \%$ had $26-50$ years old and $17 \%$ were over 50 years. An interview lasted between 20 and 45 minutes. Questions about the different types of information that could be found on the packaging were read one by one and the response options were frequently recalled. Data analysis was carried out using the software Excel and SPSS version 21. For comparison of differences regarding an ordinal variable, between two groups, we run the Mann-Whitney U test. The level of statistical significance was set at $\mathrm{p}<0.05$.

Research questions, hypotheses and objectives were established following the guidance of scientific literature (Creshwell, 2014; Farrugia et al., 2010; Morgan and Harmon, 2000). Thus, the starting research question was: "Which public policy option related to food labeling is preferred by selected stakeholders (food producers and sellers, doctors, fitness trainers and sports practitioners, and consumers), taking into account consumer current label/FOP reading behavior?" Consequently, it was necessary to add the following research question: "What is the current label reading behavior of Romanian consumers?" Because consumer behavior is a complex concept, it was necessary to clarify it by introducing the following specific questions: "Which is the level of consumers" interest on the characteristics of the food they buy?"; "Which is the reading frequency of different types of information on food label/FOP when consumers buy food?"; "Which is the reading frequency of different types of information on food label/FOP after the food is bought?"; "How often do consumers replace a product as a consequence of missing information on the label/FOP?";to better understand studied population the following was also asked: "Is there a difference between women and men regarding studied variables?" The research hypotheses were: "Food labels are rarely read by consumers" (where "rare" meant in less than $20 \%$ of shopping opportunities for at least $50 \%$ of tested consumers) and "Other public policy options than «Do Nothing» are preferred by stakeholders." The objectives were to investigate Romanian food consumer label reading behavior and to determine stakeholders' preference for a type of public policy on labeling.

Firstly, authors aimed to know the level of the reading frequency of different types of information on food label/FOP. The collection of information on a product can take place before, during or after the purchasing moment. In the case of food, this usually refers to the following occasions: reading the information on the label/FOP in the store, while shopping, just before buying the product, and reading the label/FOP information after purchasing, at home, when consumers use/eat the food item. Consequently, reading frequency of label/FOP information was tested for both occasion - at the buying moment and after purchasing (Figure no. 1). 


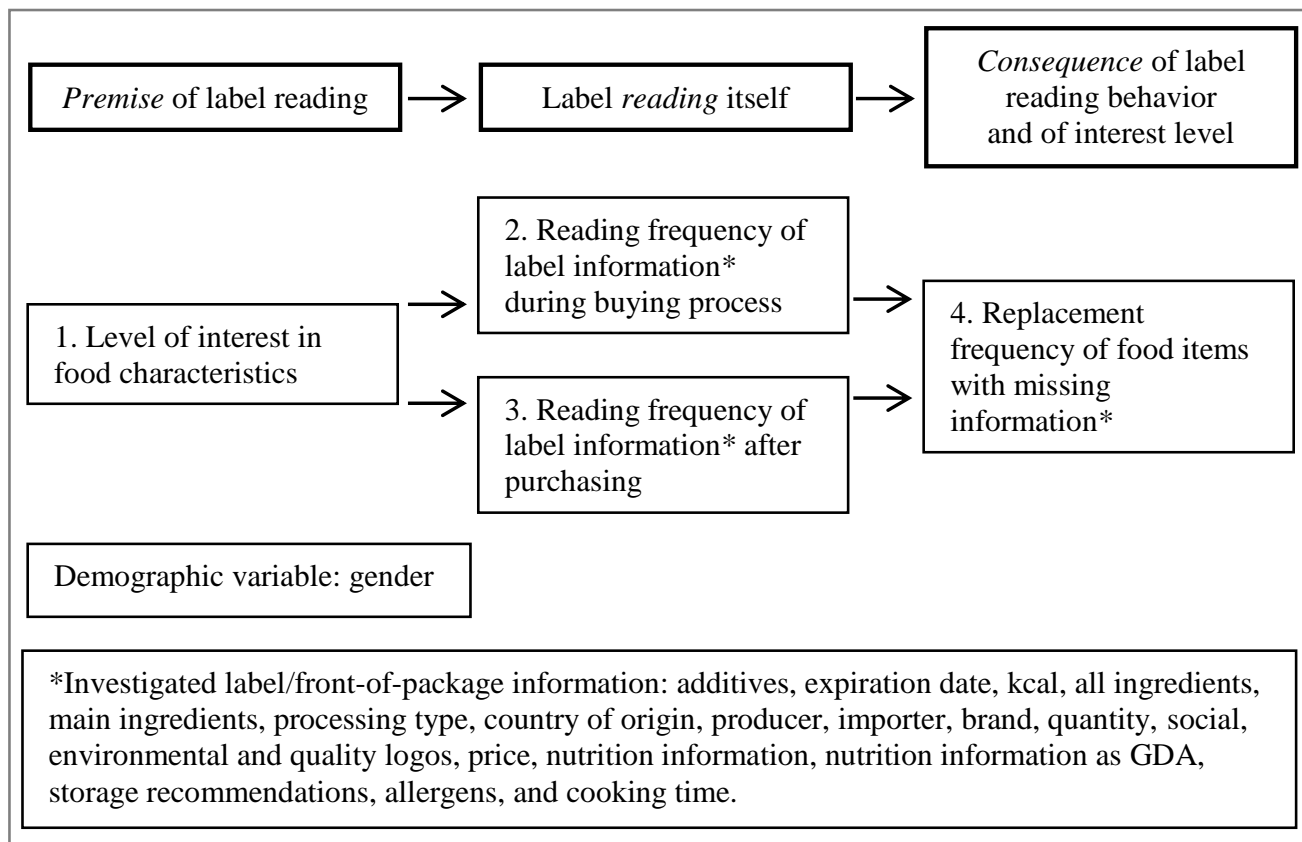

Figure no. 1: The variables used to characterize consumer food label/FOP reading behavior

As label reading is not an isolated act, but instead, it has premises and consequences, both of these were taken into account (Figure no. 1). Thus, among the factors that have an influence on performing an action (reading the label in our case), the interest is one of the most important. Therefore, consumers' interest in the characteristics of the food they buy was investigated as a premise of label reading behavior; they were asked to declare their level of interest in the characteristics of the food they buy, on a 5-points Likert scale from very low to very high. Bringing the rationale further, it was considered that the effects of reading the label information were divers, from buying or rejecting the product to acquiring information for covering future needs. Among these, the most relevant for the reading behavior was considered to be the rejection or replacement of the product with missing information, because these actions highlighted the importance of the information on the buying decision and of the action of reading it. In this context, the replacement frequency was also included in the analysis and consumers were asked how often they replaced a product for which a certain type of information was not provided on the label/FOP (Figure no. 1).

Based on the fact that consumers may manifest very different levels of interest toward different types of food attributes, a list of label information types (and not a general formulation of only one question about "label information" as a whole) was introduced in the questionnaire. Based on a review of relevant publications (e.g., Ollberding, Wolf and Contento, 2011; Ababio, Adi and Amoah, 2012; Bandara et al, 2016) and on an empirical study regarding which information was most often displayed on food labels/FOP on the Romanian market, the following list of types of information were included in the survey: additives, expiration date, number of calories, all ingredients, main ingredients highlighted, processing type (raw, pre-cooked, fried, etc.), country of origin, producer, importer, brand, 
quantity, social, environmental or quality logos (such as Fair Trade, Organic food, Protected Designation of Origin, Protected Geographical Indication, Traditional Speciality Guaranteed, or Traditional Product), price, nutrition information (as quantities), nutrition information as Guideline Daily Amounts (GDA), storage recommendations, allergens, and cooking time (Figure no. 1). These variables were assessed using self-estimation provided by consumers. They were asked to evaluate, under the form of percentage, how often they read each piece of information in the total number of purchasing occasions that occurred during the last year (for each of the three situations: at the buying moment, after acquisition, and when they replaced the product with missing information). The answer options were $0-20 \%, 21-40 \%, 41-60 \%, 61-80 \%, 81-100 \%$ of the occasions when they bought food during the last 12 months.

Secondly, after the completion of the investigation on label reading behavior, the research advanced toward the assessment of several public policy options. In the present paper, the authors used the generic meaning of "public policy" which may refer, for example, to "policies as specific proposals", "policies as products", "policies as theories and models" and "policies as processes" (Miroiu, 2001).Three public policy options were compared through matrix evaluation; two of theminclude the implementation of specific measures (mandatory introduction of TLLs and mandatory use of SIM with health claims), and one represents the perpetuation of the current situation - "Do nothing". Among the possible instruments to asses a public policy, the evaluation matrix was selected, being suitable in the case of subjective criteria, frequently present in health public policies, as those dedicated to food safety. Evaluation matrix allows decision makers to evaluate, compare and select a solution among several variants. The aim is to discover that option which can stimulate consumers to adopt a healthier diet. The three options were evaluated against five criteria: health benefits for consumers; educational benefits(better informed consumers); monetary gains for consumers (e.g., lower health expenses due to better health state); monetary gains for food chain actors (grower, processor, manufacturer, distributor/ wholesaler, and retailer); and image benefits for food chain actors. The evaluations were made by four groups of stakeholders - food producers and sellers, doctors, fitness trainers and sports practitioners, and consumers. The selection of these stakeholder categories was made by the authors taking into account the level of interest in food, nutrition and health issues and the level of information about them. Each group was represented by three individuals. They were asked to evaluate the criteria on a scale from 1 (no effect) to 10 (very high effect) for each policy option. They also assigned importance to each criterion, on a scale from 1 (not at all important) to 10 (extremely important) which expressed how important was a criterion to a labeling policy (in general) dedicated to food safety. These evaluations were carried out in a series of meetings involving between 1 and 4 persons.

\section{Results and discussion}

Results and discussions are structured on two sections, namely one focused on consumer label reading behavior and one dedicated to public policies options designed to promote food safety.

\subsection{Consumer label/FOP reading behavior: premises, actual reading, and consequencesof label reading}

Consumers' interest in food characteristics is linked to their awareness, understanding, and reading of food label/FOP information and they all represent an important safety and health 
issue (Ababio, Adi and Amoah, 2012) which must be considered as a basis of any public policy dedicated to food safety and consumer health. The list of information used to investigate consumer reading behavior had 18 components. In order to test the reliability of the scale, the internal consistency was measured using the Cronbach's coefficient alpha. The average correlation among all of the items that made up the scale was good - higher than the minimum level 0.7. Thus, the Cronbach alpha coefficient was 0.857 for reading frequency at purchase, 0.925 for reading frequency after acquisition, and 0.917 for frequency of replacing the product when a piece of information was missing.

The present paper revealed that Romanian consumers declared themselves as being interested in the characteristics of the food they bought and ate (Table no. 1), even if this interest does not have a maximum level. Thus, a strong premise for taking the action on reading the information on the label is created, allowing the food label to be a valuable communication tool between consumers and food manufacturers (Ababio, Adi and Amoah, 2012).

Table no. 1: Label reading behavior (scores)

\begin{tabular}{|c|c|c|c|c|}
\hline & $\begin{array}{l}\text { Interest in food } \\
\text { characteristics }\end{array}$ & $\begin{array}{l}\text { Label reading } \\
\text { frequency at the } \\
\text { purchasing } \\
\text { moment }\end{array}$ & $\begin{array}{l}\text { Label reading } \\
\text { frequency after } \\
\text { purchasing }\end{array}$ & $\begin{array}{l}\text { Product replacement } \\
\text { frequency determined } \\
\text { by missing information } \\
\text { on the label }\end{array}$ \\
\hline Score* & 3.7 & 3.1 & 2.5 & 2.4 \\
\hline
\end{tabular}

Further on, this level of interest was confirmed by the reading frequency of label information declared by people (Table no. 1). In order to analyze collected data, reading frequencies were coded as follows: $1=0-20 \%, 2=21-40 \%, 3=41-60 \%, 4=61-80 \%$, and $5=81-100 \%$ of the occasions when consumers bought food. The highest self-estimated reading frequency declared by consumers belonged to "expiration date" and "price", closely followed by "quantity" and "brand", while the "allergens", "social, environmental, and quality labels", and "importer name" were on the last places (Table no. 2 and Figure no. 2). Comparatively, in Turkey, the most frequently used label information was "brand" (read by $86.9 \%$ of people) and "sell by date" ( $86.4 \%$ of people) (Besler et al., 2012). Ingredients, which are among the most investigated variables, were read by $83 \%$ of tested Romanian consumers, in at least $21 \%$ of the cases when they bought food (Table no. 2). The percentage is considerably higher compared to other studies: for instance, $51.6 \%$ of the US consumers declared they read the ingredients (Ollberding, Wolfand Contento, 2011) and $47.3 \%$ of Turkish consumers used the ingredients list (Besler, Buyuktuncer and Uyar, 2012). Additives represent a topical debate at EU level, strongly related to food safety, and the level of reading frequency revealed by the current paper confirms Romanian consumers' concern about them: 97\% of consumers read them in at least $21 \%$ of food purchasing occasions (Table no. 2). Similarly, Spanish consumers were very preoccupied with additives and assigned them the first place among their interests (Prieto-Castillo, Royo-Bordonada and Moya-Geromini, 2015). If we order the reading frequencies from the highest to the lowest, it can be observed that nutrition and ingredients are ranked on the fifth and eighth positions out of twelve. Thus, judging in a comparative context, reading habits targeting these pieces of information and, consequently, interest for nutrition aspects should be enhanced. 
Food safety requires that consumers keep on paying attentionto food characteristics even after purchasing. This may refer to label reading in order to ensure that the product complies with consumer's GDA, that it respects the expiration date and it is stored and cooked in proper conditions, or that the food item responds to health requirements that may intervene after acquisition. In other words, food safety monitoring through label reading remains important "from supermarket to plate". The results of the present research showed that, as expected, after purchasing, the most frequently read pieces of information on the label were "cooking time", "expiration date", and "quantity" (Table no. 2 and Figure no. 2), among which the last two may communicate the interest in food safety issues.

The importance of label information to consumer is incorporated in consumer behavior, through actions such as acquisition of product when consumer finds out by reading the label that it fulfills his/her requirements, replacement of product in case of missing label information, or even grievances to consumer protection bodies. Tested consumers proved to react often to missing information about "expiration date" because $82 \%$ of them replaced the product with missing information in at least $21 \%$ of cases when they bought food (Table no. 2). The weakest reaction was triggered by "importer name", "social, ecological and quality labels", and "allergens" (Table no. 2), suggesting the need of informationeducation campaigns to raise awareness on traceability importance and special logos meaning (which are not a priority not even at the buying moment; Table no. 2). The results should also be interpreted as an alarm signal for manufacturers, as they show to them that they can be sanctioned by consumers if the product, judged through the lens of label/FOP information, does not meet consumers' demands.

Table no. 2: Label reading frequency and product replacement frequency (percentage of total sample)

\begin{tabular}{|l|l|l|l|l|l|l|l|l|l|l|l|l|l|l|l|l|}
\hline $\begin{array}{l}\text { Type of tested } \\
\text { information }\end{array}$ & \multicolumn{3}{|c|}{$\begin{array}{l}\text { Label reading frequency } \\
\text { during purchasing }\end{array}$} \\
\hline $\begin{array}{l}\text { Leading/ change } \\
\text { frequency* }\end{array}$ & 1 & 2 & 3 & 4 & 5 & 1 & 2 & 3 & 4 & 5 & 1 & 2 & 3 & 4 & 5 \\
\hline Additives & 16 & 18.9 & 23.7 & 2.1 & 19.2 & 37.8 & 22.4 & 17.0 & 14.1 & 8.7 & 40.7 & 21.8 & 14.1 & 14.7 & 8.7 \\
\hline Expiration date & 4.2 & 2.6 & 11.2 & 22.8 & 59.3 & 14. & 7.7 & 13.1 & 19.6 & 45.5 & 18.3 & 11.5 & 9.0 & 17.9 & 43.3 \\
\hline No. of calories & 21.5 & 25.6 & 16.0 & 22.8 & 14.1 & 30.8 & 24.4 & 19.9 & 11.5 & 13.5 & 42.0 & 25.0 & 13.1 & 12.8 & 7.1 \\
\hline All ingredients & 17 & 25.3 & 25 & 23.7 & 9.0 & 28.5 & 23.1 & 23.4 & 15.4 & 9.6 & 33.7 & 25.3 & 19.2 & 13.8 & 8.0 \\
\hline Main ingredients & 17.3 & 24.7 & 25.6 & 21.8 & 10.2 & 32.4 & 24.0 & 20.8 & 14.7 & 8.0 & 34.9 & 26.9 & 18.6 & 10.6 & 9.0 \\
\hline Processing type & 19.2 & 18.9 & 22.8 & 22.1 & 17.0 & 31.1 & 24.7 & 16.0 & 13.8 & 14.4 & 37.5 & 26.9 & 17.6 & 11.2 & 6.7 \\
\hline Country of origin & 18.9 & 27.2 & 19.6 & 20.5 & 13.8 & 38.1 & 26.6 & 16.7 & 12.5 & 6.1 & 38.8 & 34.0 & 14.1 & 8.7 & 4.5 \\
\hline Producer & 14.7 & 14.4 & 19.6 & 29.5 & 21.8 & 39.1 & 21.2 & 16.7 & 13.8 & 9.3 & 36.5 & 25.0 & 20.5 & 9.9 & 8.0 \\
\hline Importer & 29.8 & 25.6 & 19.2 & 14.4 & 10.9 & 47.4 & 20.2 & 20.2 & 7.4 & 4.8 & 44.9 & 30.1 & 15.4 & 5.1 & 4.5 \\
\hline Brand & 6.4 & 9.6 & 15.7 & 30.8 & 37.5 & 30.8 & 18.3 & 20.5 & 17.3 & 13.1 & 30.8 & 18.6 & 22.4 & 16.0 & 12.2 \\
\hline Quantity & 4.8 & 5.8 & 17.0 & 31.4 & 41.0 & 26.9 & 13.1 & 20.8 & 19.9 & 19.2 & 29.5 & 13.1 & 23.1 & 21.2 & 13.1 \\
\hline
\end{tabular}




\begin{tabular}{|c|c|c|c|c|c|c|c|c|c|c|c|c|c|c|c|}
\hline \multirow{2}{*}{$\begin{array}{l}\text { Type of tested } \\
\text { information } \\
\text { Social, } \\
\text { environmental } \\
\text { and quality logos }\end{array}$} & \multicolumn{5}{|c|}{$\begin{array}{l}\text { Label reading frequency } \\
\text { during purchasing }\end{array}$} & \multicolumn{5}{|c|}{$\begin{array}{l}\text { Label reading frequency } \\
\text { after purchasing }\end{array}$} & \multicolumn{5}{|c|}{$\begin{array}{l}\text { Replacement frequency } \\
\text { determined by missing } \\
\text { information on the label }\end{array}$} \\
\hline & 38.8 & 14.4 & 21.2 & 16.3 & 9.3 & 48.1 & 21.2 & $14.7 \mid$ & 9.3 & 6.7 & 49.4 & 25.0 & 15.7 & 6.1 & 3.8 \\
\hline Price & 2.9 & 2.2 & 12.2 & 24.0 & 58.7 & 41.3 & 20.8 & 13.1 & 11.2 & 13.5 & 23.1 & 13.5 & 17.6 & 17.0 & 28.8 \\
\hline $\begin{array}{l}\text { Nutrition } \\
\text { information }\end{array}$ & 17.3 & 18.3 & 25.0 & 18.6 & 20.8 & 32.1 & 17.6 & 23.1 & 14.1 & 13.1 & 33.7 & 24.7 & 24.4 & 10.9 & 6.4 \\
\hline $\begin{array}{l}\text { Nutrition } \\
\text { information as } \\
\text { GDA }\end{array}$ & 22.4 & 20.5 & 26.3 & 16.7 & 14.1 & 34.0 & 20.5 & 22.1 & 12.5 & 10.9 & 40.1 & 26.0 & 20.5 & 8.0 & 5.4 \\
\hline $\begin{array}{l}\text { Storage } \\
\text { recommendations }\end{array}$ & 22.8 & 27.6 & 23.7 & 17.3 & 8.7 & 34.0 & 16.0 & 19.9 & 19.6 & $10 . .6$ & 40.1 & 26.3 & 18.6 & 9.3 & 5.8 \\
\hline Allergens & 40.1 & 24.4 & 16.3 & 10.6 & 8.7 & $51 . .6$ & 22.4 & 11.2 & 7.7 & 7.1 & 50.3 & 26.3 & 12.2 & 5.4 & 5.8 \\
\hline Cooking time & 21.5 & 21.8 & 19.6 & 21.2 & 16.0 & 26.9 & 14.4 & 19.2 & 15.4 & 24.0 & 40.7 & 21.2 & 19.6 & 10.9 & 7.7 \\
\hline
\end{tabular}

After analyzing data from Table no. 2, Figure no. 2 was drafted, in order to quicker obtain a general image of the situation. Here, the scores of each type of information in the three investigated moments are presented - during purchasing ("Buy'), after purchasing ("After"), and product replacement frequency due to lack of information on the label ("Missing").The scores were calculated by assigning values from 1 to 5 to the frequencies of label reading and of product replacement (as it is explained in the legend of Table no. 2) and by calculating the mean value for the sample.

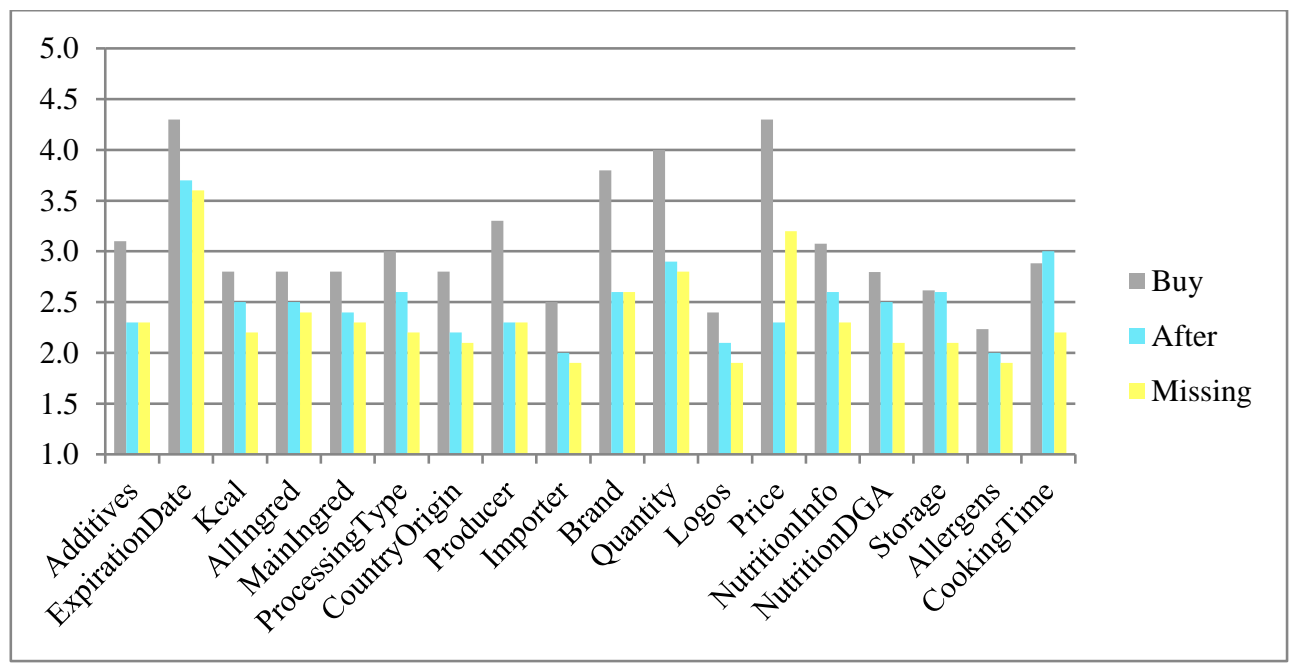

Figure no. 2: Label reading frequency and product replacement frequency (mean scores on a scale from 1 to 5) 
Gender did not have an influence on most of the investigated variables ( $>>0.05)$. Only the following statistically significant differences were found: women read the label more often than men in case of "expiration date" (at purchasing and after purchasing) and "processing type" (at purchasing), while men declared higher reading frequencies in case of "producer name" (at purchasing and after purchasing), and "importer name" (after purchasing); the frequency of product replacement was higher for women in case of "processing type" and for men in case of "producer name" $(\mathrm{p}<0.05)$.

\subsection{Public policy options on labeling designed to promote food safety}

Practical realities show us that there is a significant gap between the ways institutions make policies and the available knowledge on how policies can best be made (Dror, 1983). Therefore, to serve the public best interest, the aim of this paper is to develop and assess a set of public policy options designed to increase awareness and improve consumers' life from the food safety point of view, thus fueling with knowledge future policy-making process. Defined as "political decisions for implementing programs to achieve societal goals" (Cochran and Malone, 1995), a new public policy in the field of food safety may ameliorate citizens' health state, in a context where health expenditure in the EU accounts for around $10 \%$ of GDP and almost $15 \%$ of public spending (European Commission, 2007). The efforts to combat the trend of increasing number of people with nutrition and metabolic diseases require to increase food consumers awareness on the relationship between nutrition and health and on the basic principles of a balanced diet (Popescu, Voinea and Negrea, 2015), and this can be supported by policy measures. Therefore, based on the fact that there is an association between label use and healthy eating (such as lower fat consumption) (Kim, Nayga and Capps, 2001; Kim and Douthitt, 2004), the herein presented public policy options aim to support a healthier lifestyle through the effect that more efficient labeling can have on consumer food choice.

The following three policy options were selected for this analysis: the mandatory introduction of traffic light labels (TLLs); the mandatory use of social interest messages (SIMs) with health claims; the continuation of the current situation, which represents the adoption of "Do nothing" option.

A general motivation for taking under analysis the first two policy options was that, based on the survey results, consumers do not pay sufficient attention to information related to nutrition that has the potential to positively impact on their health (e.g., calories, ingredients lists, allergens).

- TLLs indicate high, medium, and low levels of certain nutrients (e.g., calories, sugar, saturated fats and salt) through red, amber, and green colors, respectively, and also provide numerical values in either grams per portion or per 100g (Hawley et al., 2013). The reason to select TLLs was their suitability for consumers: they declared better understanding of labels that are color-coded (Kelly et al., 2009) and TLLs increased consumers' ability to correctly determine if a food was healthy (Gorton et al., 2009). Referring to the present research, the fact that the nutritional information and the ingredients are ranked fairly low within studied population, on the fifth and eighth positions out of twelve places, justifies the choice of a public policy aimed at introducing mandatory TLLs - as these labels attract the attention of the consumer and make the reading and understanding of information easier. Thus, it is possible to translate the results of the survey on the of label reading behavior into public policy scenarios. 
- SIMs with health claims have the objective to inform and educate and not to sell a product or service, to change public opinion and raise awareness for health issues related to food. The use of this public policy option would have the capacity to educate first and provoke an emotional and behavioral reaction after that. The following messages can be included in this category: "Eat in moderation salt, sugar and fats" (which helps preventing noncommunicable diseases, such as cardiovascular diseases and diabetes); "Clean, separate, cook, and chill" (which stimulates consumers to adopt safe food handling practices) (Anderson et al., 2004); "Exercise at least 30 minutes each day" (because physical activity reduces the risk of dying from a noncommunicable diseases).A message like "Eat in moderation salt, sugar and fats" responds to the results of this research, where $21.5 \%$ of interviewed people read very rarely or not at all (between $0 \%$ and $20 \%$ of the consumption situations) the amount of calories on the label, and $17 \%$ of the respondents read very rarely or not at all the ingredients, according to Table no. 2.

These two policy optionsmay have the capacity to trigger change both in consumer and producer behavior. Scientific literature mentions that producers improved the quality of their products as a consequence of the introduction of labeling rules that better highlighted some quality aspects which had the potential to influence consumer to pay more attention to food characteristics. Thus, following the adoption of a new logo system in New Zeeland, food companies excluded 33 tonnes of salt over the course of a year by adjusting their products (Young and Swinburn, 2002); in the Netherlands, the Choices nutrition logo motivated food manufacturers to offer healthier products by reformulating existing products and developing new ones with lower sodium and higher dietary fiber (Vyth et al, 2010).

- The reference scenario against which the two policy options mentioned above were compared was "Do nothing" option. This represents the continuation of the current situation (path-dependence) and it is often preferred by decision-makers, who are trapped in a path-dependence behavior and do not want to assume new responsibilities, because change can require investments, new learning processes and adaptation to new situations (Palier and Bonoli, 1999; Trouvé et al., 2010).

The first two policy options can be easily integrated in the category of public policies. Thus, there are several key components that should be present when talking about of a public policy (Birkland, 2015). For example, both options are made to respond to a problem that claims attention - food safety focused on consumer health; they are made for the public benefit - each citizen is, at a certain moment a food buyer and consumer; they are oriented to a solution - improved public health through better food choices that are supported by food label reading; and, finally, they are what government chooses to do or not to do.

Following the matrix evaluation steps, stakeholders assigned a score between 1 (the weakest) and 10 (the best) for each criterion within each option. This resulted in 269.8 points (representing around $66 \%$ of maximum number of points) for TLLs public policy option, while the second option accumulated 233.6 points and "Do nothing" received 148.6 points (Table no. 3 and Table no. 4). Both TLLs and SIMs seem to have public support in case they would be translated into practice. The high score obtained indicate a clear preference of interviewed stakeholders toward change in the field of food labeling, creating the premises for securing consumer health through foodstuff labels. 
Table no. 3: Evaluation of all criteria for all policy options made by the representatives of stakeholders groups

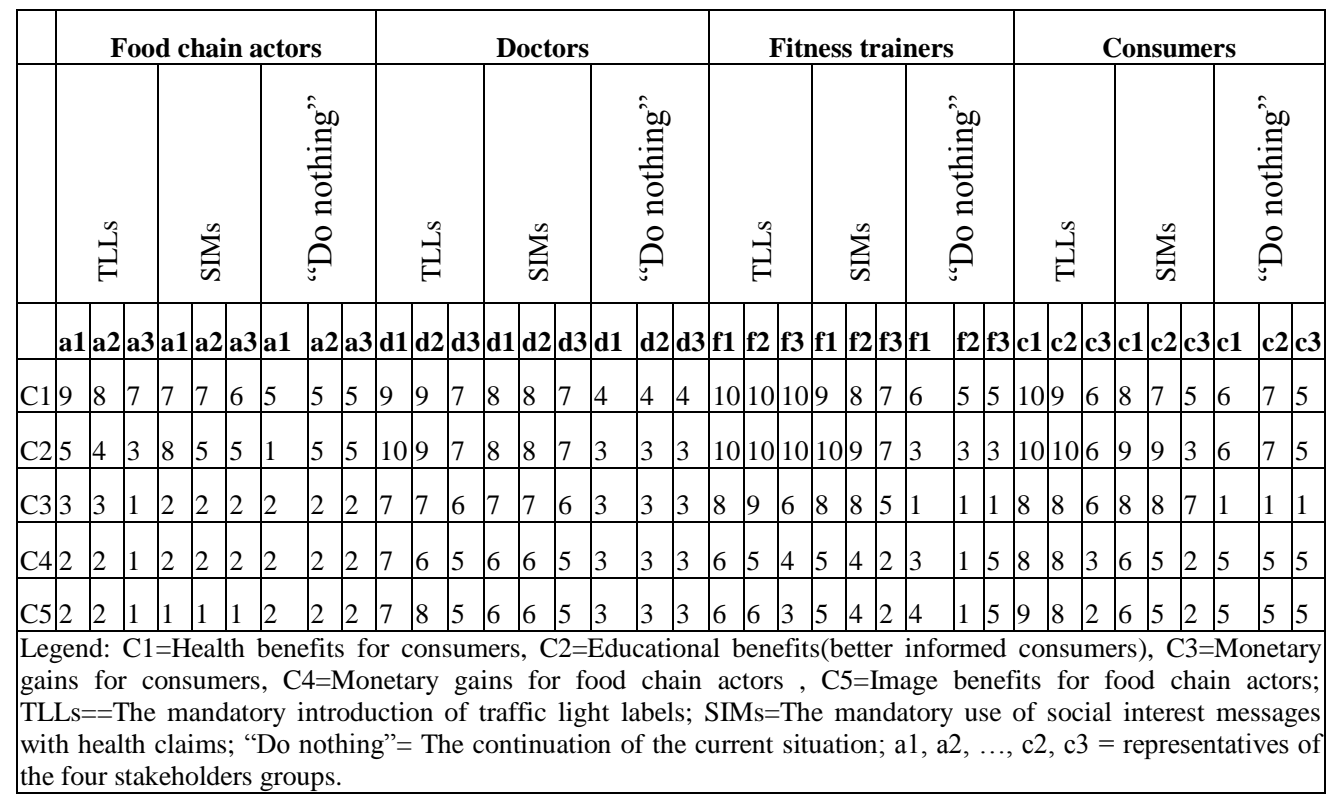

Table no. 4: Weighted scores of public policy options

\begin{tabular}{|l|c|c|c|c|}
\hline $\begin{array}{l}\text { Criteria/Policy options } \\
\text { and Importance of criteria }\end{array}$ & TLLs & SIMs & “'Do nothing" & Importance of criteria** \\
\hline C1 & $8.7 *$ & 7.3 & 5.1 & 10.0 \\
\hline C2 & 7.8 & 7.3 & 3.9 & 8.8 \\
\hline C3 & 6.0 & 5.8 & 1.8 & 6.2 \\
\hline C4 & 4.8 & 3.9 & 3.3 & 8.0 \\
\hline C5 & 4.9 & 3.7 & 3.3 & 7.9 \\
\hline $\begin{array}{l}\text { Weighted scores } \\
\text { of policy options }\end{array}$ & $\mathbf{2 6 9 . 8 * * *}$ & $\mathbf{2 3 3 . 6}$ & $\mathbf{1 4 8 . 6}$ & \\
\hline $\begin{array}{l}\text { Legend: see Legend explained in Table no. 3 } \\
* 8.7=(9+8+7+9+9+7+10+10+10+10+9+6) / 12 ; 7.3=(7+7+6+8+8+7+9+8+7+8+7+5) / 12 ; * *=a v e r a g e\end{array}$ \\
importance awarded by all participants; $* * * 269.8=8.7 \times 10+7.8 \times 8.8+6.0 \times 6.2+4.8 \times 8.0+4.9 x 7.9$. \\
\hline
\end{tabular}

\section{Conclusions}

The present paper advances findings about consumer label reading behavior and stakeholders preferences for several public policy options in the field of food safety. The survey profiled a consumer interested in the features of the food he/she buys, who reads information on the food label/FOP (expiration date among the most frequently), but who does not pay sufficient attention to nutrition section of the label, thus justifying an intervention through a public policy, such as one introducing mandatory traffic light labels or social interest messages with health claims. Investigated stakeholders (food producers 
and sellers, doctors, fitness trainers and sports practitioners, and consumers) were very receptive to both of these options, rewarding them with high scores.

Although these results are encouraging, there are several limitations which should be addressed in future related research. Thus, the sample size used to investigate label reading behavior can be increased and the range of public policy options can include more possibilities (such as the new system introduced in France - "Nutri-score", based on five colors, or that from Australia - "Health Stars Ratings", which uses a rating system on a 5star scale). With regard to the methodology, a methodological mix could be used to include, for example, public policy assessments using cost-benefit analysis to achieve maximum benefits at minimal cost. Also, the diversification of stakeholder categories (to others, such as NGOs and public authorities) and the inclusion of a representative sample would increase the accuracy of the resulting knowledge.

Labeling intervention through public policies - destined to serve the best interest of each citizen - intend to disclose food characteristics, assisting consumers in adopting healthier diets, and, at the same time, stimulating the actors of the food chain to reinvent their products to be healthier (e.g., by changing ingredients or quantities, reducing serving size). At the same time, the results of this investigation can serve as knowledge support for decision makers who have the responsibility to act in the name and the best interest of all citizens.

\section{Acknowledgments}

This study was partially developed through the research program "The creation of a model for the evaluation of food quality from the point of view of consumer health and environmental protection", 2016-2018, selected within the bilateral cooperation between the Romanian Academy and Wallonia - WBI, FRS-FNRS. "La présente publication a été rendue possible grâce à l'Accord qui lie WBI, le FRS-FNRS et l'Académie Roumaine."

\section{References}

Ababio, P.F., Adi, D.D. and Amoah, M., 2012.Evaluating the awareness and importance of food labelling information among consumers in the Kumasi metropolis of Ghana. Food Control, 26(2), pp.571-574.

Anderson, J.B., Shuster, T.A., Hansen, K.E., Levy, A.S. and Volk, A., 2004. A camera's view of consumer food-handling behaviors. Journal of the American Dietetic Association, 104(2), pp.186-191.

Aung, M.M. and Chang, Y.S., 2014. Traceability in a food supply chain: Safety and quality perspectives. Food Control, 39, pp.172-184.

Bandara, B.E.S., De Silva, D.A.M., Maduwanthi, B.C.H. and Warunasinghe, W.A.A.I., 2016. Impact of food labeling information on consumer purchasing decision: with special reference to Faculty of Agricultural Sciences. Procedia Food Science, 6, pp.309-313.

Besler, H.T., Buyuktuncer, Z. and Uyar, M.F., 2012. Consumer understanding and use of food and nutrition labeling in Turkey. Journal of Nutrition Education and Behavior, 44(6), pp.584-591

Birkland, T.A., 2014. An introduction to the policy process: Theories, concepts and models of public policy making. London and New York: Routledge. 
Cavaliere, A., Ricci, E.C. and Banterle, A., 2015. Nutrition and health claims: Who is interested? An empirical analysis of consumer preferences in Italy. Food Quality and Preference, 41, pp.44-51.

Charles, L., Cochran, C.L. and Malone, E.F., 1995. Public Policy: Perspectives and Choices. New York: McGraw Hill.

Creshwell, J. W., 2014. Research Design. Qualitative, Quanttative, and Mixed Methods Approaches. London, United Kingdon: Sage.

Department of Health, Food Standards Agency, Welsh Government, Food Standards Scotland, 2016. Guide to creating a front of pack $(F o P)$ nutrition label for pre-packed products sold through retail outlets. [online] Available at: <https://www.gov.uk/ government/uploads/system/uploads/attachment_data/file/566251/FoP_Nutrition_labelli ng_UK_guidance.pdf> [Accessed30 November 2017].

Dror, Y., 1983. Public policy making reexamined. New Brunswick, New Jersey, USA: Transaction Publishers.

Emrich, T.E., Qi, Y., Lou, W. and L'Abbé, M.R., 2017.Traffic-light labels could reduce population intakes of calories, total fat, saturated fat, and sodium. PLoS ONE, 12(2), e0171188.

Emrich, T.E., Qi, Y., Mendoza, J.E., Lou, W., Cohen, J.E. and L'Abbé, M.R., 2014. Consumer perceptions of the Nutrition Facts table and front-of-pack nutrition rating systems. Applied Physiology, Nutrition, and Metabolism, 39(4), pp.417-424.

Emrich, T.E.and Mazier, M.J.P., 2009. Impact of Nutrition Education On University Students' Fat Consumption. Canadian Journal of Dietetic Practice and Research, 70(4), pp.187-192.

European Commission, 2007.Together for Health: A Strategic Approach for the EU 20082013. $\operatorname{COM}(2007) 630$ final. [online] Available at: <http://ec.europa.eu/health/ archive/ph_overview/documents/strategy_wp_en.pdf> [Accessed 3 August 2017].

Gorton, D., Mhurchu, C.N., Chen, M.H. and Dixon, R., 2009. Nutrition labels: a survey of use, understanding and preferences among ethnically diverse shoppers in New Zealand. Public Health Nutrition, 12(9), pp.1359-1365.

Graham, D.J., Orquin, J.L. and Visschers, V.H., 2012. Eye tracking and nutrition label use: A review of the literature and recommendations for label enhancement. Food Policy, 37(4), pp.378-382.

Grunert, K.G., Wills, J.M. and Fernández-Celemín, L., 2010. Nutrition knowledge, and use and understanding of nutrition information on food labels among consumers in the UK. Appetite, 55(2), pp.177-189.

Hawley, K.L., Roberto, C.A., Bragg, M.A., Liu, P.J., Schwartz, M.B. and Brownell, K.D., 2013. The science on front-of-package food labels. Public Health Nutrition, 16(3), pp.430-439.

Henson, S. and Traill, B., 1993.Consumer perceptions of food safety and their impact on food choice. In G. G. Birch and G. Campbell-Platt, eds. 1993.Food safety - The challenge ahead. Andover: Intercept. pp. 39-55.

Kelly, B., Hughes, C., Chapman, K., Louie, J.C., Dixon, H., Crawford, J., King, L., Daube, M. and Slevin, T., 2009.Consumer testing of the acceptability and effectiveness of frontof-pack food labeling systems for the Australian grocery market. Health Promotion International, 24(2), pp.120-129. 
Kim, S.Y. and Douthitt, R.A., 2004.The role of dietary information in women's whole milk and low-fat milk intakes. International Journal of Consumer Studies, 28(3), pp.245-254.

Kim, S.Y., Nayga, R.M. Jr. and Capps, O., 2001.Food label use, self selectivity, and diet quality. Journal of Consumer Affairs, 35(2), pp.346-363.

Kim, W. K. and Kim, J., 2009.A study on the consumer's perception of front-of-pack nutrition labeling. Nutrition Research and Practice, 3(4), pp.300-306.

Lähteenmäki, L., 2013. Claiming health in food products. Food Quality and Preference, 27(2), pp. 196-201.

Maican, O., 2015. Genetically modified organisms - European and Romanian legislation. Juridical Tribune, 5(2), pp. 60-69.

Miroiu, A. 2001.Introducere in Analiza Politicilor Publice. Bucharest, Romania: Punct.

MohdNawi, N. and Mohd Nasir, N.I., 2014. Consumers' attitude toward the food safety certificate (FSC) in Malaysia. Journal of Food Products Marketing, 20(sup1), pp.140-150.

Morgan, G.A. and Harmon, R.J., 2000, Research Questions and Hypotheses. Journal of the American Academy of Child \& Adolescent Psychiatry, 39(2), pp.261-263.

Ollberding, N.J., Wolf, R.L. and Contento, I., 2011. Food label use and its relation to dietary intake among US adults. Journal of the American Dietetic Association, 111(5), S47-S51.

Palier, B. and Bonoli, G., 1999. Phénomènes de path dependence et réformes des systèmes de protection sociale. Revue française de science politique, 49(3), pp. 399-420. [online] Available at: <http://www.persee.fr/docAsPDF/rfsp_0035-2950_1999_num_49_3_ 395383.pdf> [Accessed 2 November 2017].

Pennings, M.C., Striano, T. and Oliverio, 2014.A picture tells a thousand words: Impact of an educational nutrition booklet on nutrition label gazing. Marketing Letters, 25(4), pp.355-360.

Popescu, D.V., Voinea, L. and Negrea, M.T., 2015. Nutritional imbalance - dominant consumption behaviour of Romanian youth. Amfiteatru Economic, 17(Special No. 9), pp. 1228-1243.

Prell, H.C., Berg, M.C., Jonsson, L.M. and Lissner, L., 2015. A school-based intervention to promote dietary change. Journal of Adolescent Health, 36, pp.529-534.

Prieto-Castillo, L., Royo-Bordonada, M.A. and Moya-Geromini, A., 2015.Information search behaviour, understanding and use of nutrition labeling by residents of Madrid, Spain. Public Health, 129(3), pp.226-236.

Röhr, A., Lüddecke, K., Drusch, S., Müller, M. J. andAlvensleben, R.V., 2005. Food quality and safety-consumer perception and public health concern. Food control, 16(8), pp.649-655.

Rozin, P., Fischler, C., Imada, S., Sarubin, A. andWrzesniewski, A., 1999. Attitude to food and the role of food in life in the USA, Japan, Flemish Belgium and France: possible implications for the diet-health debate. Appetite, 33(2), pp.163-180.

Santacruz, S., 2016. What is Food Safety? Australian Institute of Food Safety. [online] Available at: <https://www.foodsafety.com.au/resources/articles/what-is-food-safety> [Accessed 30 November 2017]. 
Tarabella, A. and Voinea, L., 2013. Advantages and Limitations of the Front-of-Package (FOP) Labeling Systems in Guiding the Consumers' Healthy Food Choice. Amfiteatru Economic, 15(33), pp. 198-209.

Trouvé, H., Couturier, Y., Etheridge, F., Saint-Jean, O. and Somme, D., 2010, The path dependency theory: analytical framework to study institutional integration. The case of France. International Journal of Integrated Care, [online] Available at: <https://www.ncbi. nlm.nih.gov/pmc/articles/PMC2916113/> [Accessed 2 November 2017].

Turconi, G., Guarcello, M., Maccarini, L., Cignoli, F., Setti, S., Bazzano, R. and Roggi, C., 2008. Eating Habits and Behaviors, Physical Activity, Nutritional and Food Safety Knowledge and Beliefs in an Adolescent Italian Population. Journal of the American College of Nutrition, 27(1), pp.31-43.

Verbeke, W., Frewer, L.J., Scholderer, J. and De Brabander, H.F., 2007. Why consumers behave as they do with respect to food safety and risk information. Analytica Chimica Acta, 586(1), pp.2-7.

Vyth, E.L., Steenhuis, I.H., Roodenburg, A.J., Brug, J. and Seidell, J.C., 2010. Front-ofpack nutrition label stimulates healthier product development: a quantitative analysis. International Journal of Behavioral Nutrition and Physical Activity, 7(1), p.65.

Wartella, E., Lichtenstein, A., Yaktine, A. and Nathan, R., 2011. Front-of-Package Nutrition Rating Systems and Symbols: Promoting Healthier Choices. Washington D.C.: The National Academies Press.

WHO, 2014.Regional Office for Europe. European Food and Nutrition Action Plan 20152020 (EUR/RC64/14 + EUR/RC64/Conf.Doc./8).[online] Available at: <http://www. euro.who.int/_data/assets/pdf_file/0008/253727/64wd14e_FoodNutAP_140426.pdf> [Accessed 1 September 2017].

WHO, 2015. Healthy diet. Fact sheet $N^{\circ} 394$. [online] Available at: <http://www.who.int/ mediacentre/factsheets/fs394/en/> [Accessed 30 November 2017].

WHO, 2017a. France becomes one of the first countries in Region to recommend colourcoded front-of-pack nutrition labelling system. [online] Available at: $<$ http://www.euro.who.int/en/countries/france/news/news/2017/03/france-becomes-oneof-the-first-countries-in-region-to-recommend-colour-coded-front-of-pack-nutritionlabelling-system> [Accessed 30 November 2017].

WHO, 2017b.Malnutrition.Fact sheet. [online] Available at: <http://www.who.int/ mediacentre/factsheets/malnutrition/en/> [Accessed 1 September 2017].

WHO, 2004.Global strategy on diet, physical activity and health. [online] Available at: <http://www.who.int/dietphysicalactivity/strategy/eb11344/strategy_english_web.pdf> [Accessed 1 September 2017].

Wilcock, A., Pun, M., Khanona, J. and Aung, M., 2004. Consumer attitudes, knowledge and behaviour: a review of food safety issues. Trends in Food Science \& Technology, 15(2), pp.56-66.

Young, L. and Swinburn, B., 2002.Impact of the Pick the Tick food information programme on the salt content of food in New Zealand. Health Promotion International, 17(1), pp.13-19. 